\title{
Regular Feedback on the Inter-Hospital Transfer Improved the Quality and Survival in Patients with Multiple Trauma: A Retrospective Cohort Study
}

Chih Jung Wang

National Cheng Kung University Hospital https://orcid.org/0000-0002-7625-2891

Tsung-Han Yang

National Cheng Kung University Hospital

Kuo-Hsu Hung

National Cheng Kung University Hospital

Chun-Hsien Wu

National Cheng Kung University Hospital

Shu-Ting Yen

National Cheng Kung University Hospital

Yi-Ting Yen ( $\sim$ b85401067@gmail.com )

National Cheng Kung University Hospital

Yan-Shen Shan

National Cheng Kung University College of Medicine

Research article

Keywords: trauma, transfer, inter-hospital, feedback, quality

Posted Date: September 14th, 2020

DOl: https://doi.org/10.21203/rs.3.rs-74146/v1

License: (9) (i) This work is licensed under a Creative Commons Attribution 4.0 International License.

Read Full License 


\section{Abstract}

Background: Under-triage of major trauma patients has been unavoidable, especially in the trauma system of rural area. Timely stabilization and transfer of critical trauma patients remains a great challenge for hospitals limited in resources for major trauma management. No definitive measure has been proved to improve the outcome of transferred major trauma patients. Current study hypothesized that regular feedback on inter-hospital transfer of patients with major trauma can improve care quality and outcome.

Method: This retrospective cohort study retrieved the transferred trauma patients with injury severity score(ISS) $\geq 16$ between Jan 2010 and Dec 2018 from the trauma registry databank of a tertiary medical center. Regular monthly feedback on inter-hospital transfer was initiated since 2014. The patients were divided into the without-feedback group and the with-feedback group. The demographic data, management before transfer, and outcome after transfer were collected and analyzed.

Results: A total of 178 patients were included; 69 patients in the without-feedback and 109 in the withfeedback group. The with-feedback group had higher ISS ( 25 vs $27, p=0.049)$, and more patients needing massive transfusion $(14.49 \%$ vs $29.36 \%, p=0.036)$. After adjusted for confounding factors, the with-feedback group was associated with higher rate of blood transfusion before transfer (adjusted odds ratio [aOR] 2.75, 95\% $\mathrm{Cl}$ [1.01-7.52], $\mathrm{p}=0.049)$, shorter time span before blood transfusion $(-31.80 \pm 15.14$, $\mathrm{p}=0.038)$, and decreased mortality risk (aOR $0.33,95 \% \mathrm{Cl}[0.13-0.83], \mathrm{p}=0.019)$.

Conclusion: This retrospective cohort study revealed that regular feedback on inter-hospital transfer improved the quality of blood transfusion and was associated with decreased mortality risk.

\section{Background}

Trauma injury is a global problem, and even in the next decade it will still be the main cause of mortality in the world.[1, 2] Trauma is one of the first medical specialties to develop regionalization, with criteria for transfer to dedicated trauma centers and the ability to track outcomes at these centers. A level I trauma center effectively decreases mortality rate of trauma patients. $[3,4]$ Inclusion of regional trauma centers into the trauma system may facilitate timely transfer of the severely injured patients and also decrease the overall mortality rate. $[3,5-7]$ Nonetheless, delayed transfer and prolonged process of transfer with inadequate initial resuscitation of major trauma patient are still a problem. [8-10] Without feedback from the receiving hospital and specialists in trauma care, there can be no room for improvement.

Hospitals in Taiwan are not equally facilitated with specialized trauma surgeons and capabilities. Despite the nationwide coverage of health insurance system, patients suffering from major trauma in rural areas might be resuscitated and then transferred to level I trauma centers. The accreditation of trauma and acute care system started in 2010, and hospitals have been graded according to their capabilities in the management of patients with multiple trauma. Our hospital has been graded as a level 1 trauma center since then, and been responsible for patient transferred from regional referring hospitals. During the last 
few years, peer review and feedback have been integral to medical education, improvement of skills, clinical judgement, and system development. We herein retrospectively analyzed the quality of resuscitation and outcome, and the impact of regular feedback in multiple trauma patients referred from regional hospitals.

\section{Material And Methods}

Feedback on inter-hospital transfer was initiated in 2014 on a monthly basis, taking turns among the referring hospitals. Patients' characteristics and demographics were retrieved from the database of trauma registry between January in 2010 and December in 2018. Patients transferred right after initial resuscitation for multiple trauma in regional hospitals were included, excluding those younger than 15 years old, those with injury severity score less than 15, and those staying longer than 12 hours in regional hospitals.

The inter-hospital transfer duration (IHTD) was defined as the time between patient's arrival at the emergency department (ED) of regional hospital and our hospital. Patient's need for transfusion was defined as transfusion of blood component after patient's arrival at the ED of regional hospital or our hospital. The time span before blood transfusion (TSBT) was defined as the duration between patient's arrival at the ED of regional hospital and transfusion of first unit of packed red blood cells (PRBCs).

Continuous data were analyzed using the Mann-Whitney $\mathrm{U}$ test as appropriate, and categorized data were analyzed using the chi-square test or Fisher's exact test. Linear regression and logistic regression were performed as univariate and multivariable analyses for continuous and categorized outcome respectively.

\section{Results}

There were 69 patients in the before-feedback group and 109 patients in the after-feedback group. There was no difference in age and gender between these two groups. The with-feedback group has higher injury severity score (ISS) (25 versus $27, \mathrm{p}=0.0499$ ), with more patients necessitating transfusion of PRBC at least 12 units $(14.49 \%$ versus $29.36 \%, p=0.036)$. The with-feedback group had more patients undergoing cardiopulmonary resuscitation (one, $1.45 \%$ versus eight, $7.34 \%$ ), but the difference was not significant $(p=0.156)$. The ratio of patients with shock index $\geq 0.9$ in regional hospital increased from $20.29 \%$ before feedback to $34.91 \%$ after feedback $(p=0.056)$. (Table 1$)$ 
Table 1

Patient demographics and outcomes

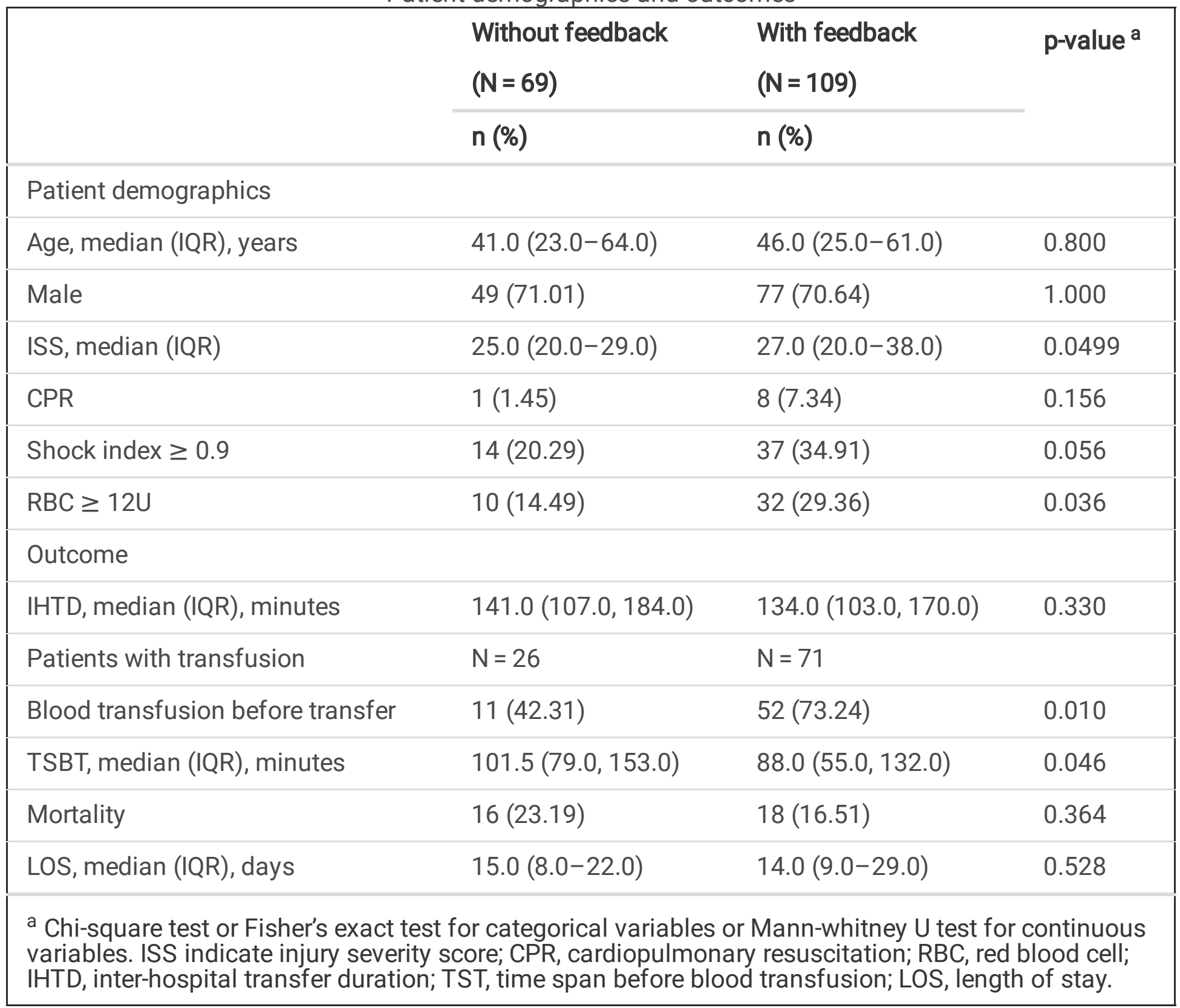

The inter-hospital transfer duration (IHTD) did not decrease in the with-feedback group. The proportion of patients receiving blood transfusion before transfer increased from $42.31-73.24 \%(p=0.010)$. The time span before blood transfusion (TSBT) decreased significantly from 101.5 minutes to 88.0 minutes $(p=$ 0.046). There was no difference in the crude mortality, length of stay, and intensive care unit days between the two groups.

Regular feedback and ISS were factors associated with the time span before PRBC transfusion in univariate analysis, whereas regular feedback was independently associated with the time span before blood transfusion ( $\beta$ : -31.80, SE: 15.14) in multivariable regression model. (Table 2) Regular feedback, ISS and Shock index $\geq 0.9$ in regional hospital ER were factors associated with blood transfusion before 
transfer. Regular feedback was independently associated with blood transfusion before transfer in multivariable regression model $(\mathrm{OR}=2.75, \mathrm{p}=0.049$, $[95 \% \mathrm{Cl}, 1.01-7.52])$. (Table 3$)$

Table 2

Univariate and multivariable analysis for factors affecting time span before blood transfusion (minutes)

\begin{tabular}{|lllll|}
\hline \multicolumn{3}{|c|}{ Univariate model } & \multicolumn{2}{c|}{ Multivariable model $^{\text {a }}$} \\
\hline Variables & $\beta \pm$ SE & $p$-value & $\beta \pm$ SE & $p$-value \\
\hline Feedback: with v.s. without & $-36.94 \pm 15.13$ & 0.016 & $-31.80 \pm 15.14$ & 0.038 \\
\hline Age: $\geq 45$ v.s. $<45$ & $4.74 \pm 13.83$ & 0.733 & & \\
\hline Male v.s. female & $19.12 \pm 16.38$ & 0.246 & & 0.053 \\
\hline ISS & $-1.20 \pm 0.52$ & 0.023 & $-1.01 \pm 0.52$ & \\
\hline Pre-transfer CPR & $-32.48 \pm 26.49$ & 0.223 & & \\
\hline Shock index: $\geq 0.9$ v.s. $<0.9$ & $-25.11 \pm 14.16$ & 0.080 & & \\
\hline $\begin{array}{l}\text { a Multivariable linear regression analysis of variables (Intervention variable \& p-value < } 0.05 \text { in } \\
\text { univariate linear regression). ISS indicate injury severity score; CPR, cardiopulmonary resuscitation }\end{array}$ \\
\hline
\end{tabular}

Table 3

Univariate and multivariable analysis for factors affecting blood transfusion before transfer

\begin{tabular}{|lllll|}
\hline Variables & $\begin{array}{l}\text { Crude OR } \\
(95 \% \mathrm{Cl})\end{array}$ & p-value & $\begin{array}{l}\text { Adjusted OR } \\
(95 \% \mathrm{Cl})\end{array}$ & p-value \\
\hline Feedback: withv.s. without & $3.73(1.46-9.54)$ & 0.006 & $2.75(1.01-7.52)$ & 0.049 \\
\hline Age: $\geq 45$ v.s. $<45$ & $0.85(0.37-1.97)$ & 0.709 & & \\
\hline Male v.s. female & $1.38(0.52-3.67)$ & 0.513 & & 0.088 \\
\hline ISS & $1.05(1.01-1.09)$ & 0.023 & $1.04(1.00-1.08)$ & \\
\hline Pre-transfer CPR & $1.38(0.25-7.52)$ & 0.710 & & 0.019 \\
\hline Shock index: $\geq 0.9$ v.s. $<0.9$ & $4.80(1.74-13.25)$ & 0.002 & $3.55(1.23-10.23)$ & \\
\hline $\begin{array}{l}\text { a Multivariable logistic regression analysis of variables (Intervention variable \& } \mathrm{p} \text {-value < } 0.05 \text { in } \\
\text { univariate logistic regression). ISS indicate injury severity score; CPR, cardiopulmonary resuscitation }\end{array}$ \\
\hline
\end{tabular}

In univariate analysis, ISS, cardiopulmonary resuscitation before transfer and transfusion of RBC $\geq 12$ unit were factors associated with higher mortality rate. After adjustment for ISS, CPR before transfer and massive transfusion of RBC, regular feedback was the independent factor associated with decreased mortality risk $(\mathrm{OR}=0.33, \mathrm{p}=0.019,[95 \% \mathrm{Cl}, 0.13-0.83])$. (Table 4) 
Table 4

Univariate and multivariable analysis for factors predicting mortality

\begin{tabular}{|lllll|}
\hline Variables & $\begin{array}{l}\text { Crude OR } \\
(95 \% \text { Cl) }\end{array}$ & p-value & $\begin{array}{l}\text { Adjusted OR }{ }^{\text {a }} \\
(95 \% \text { Cl) }\end{array}$ & p-value \\
\hline Feedback: withv.s. without & $0.66(0.31-1.39)$ & 0.272 & $0.33(0.13-0.83)$ & 0.019 \\
\hline Age: $\geq 45$ v.s. $<45$ & $1.16(0.55-2.45)$ & 0.703 & & \\
\hline Male v.s. female & $1.75(0.71-4.32)$ & 0.223 & & 0.025 \\
\hline ISS & $1.06(1.03-1.09)$ & $<0.001$ & $1.04(1.01-1.07)$ & 0.086 \\
\hline Pre-transfer CPR & $6.03(1.53-23.84)$ & 0.010 & $3.95(0.82-18.96)$ & 0.004 \\
\hline RBC: $\geq 12$ U v.s. $<12 U$ & $5.63(2.52-12.56)$ & $<0.001$ & $4.18(1.59-11.00)$ & \\
\hline Shock index: $\geq 0.9$ v.s. < 0.9 & $1.51(0.68-3.36)$ & 0.313 & & \\
\hline $\begin{array}{l}\text { a Multivariable logistic regression analysis of variables (Intervention variable \& p-value < } 0.05 \text { in } \\
\text { univariate logistic regression). ISS indicate injury severity score; CPR, cardiopulmonary resuscitation; } \\
\text { RBC, red blood cell }\end{array}$ & & & \\
\hline
\end{tabular}

\section{Discussion}

Our study demonstrated that regular feedback on the inter-hospital transfer improved the quality of blood transfusion on initial resuscitation. Patients with major trauma were more likely to be transfused with packed RBC on arrival at the emergency department of regional hospital when the feedback on interhospital transfer was done on a monthly basis. Although the time span before transfer was not decreased, because of the increased percentage of blood transfusion before transfer, the mortality risk was reduced. (Fig. 1)

Undertriage of major trauma patients has been a common problem, and inter-hospital transfer remains a great challenge of trauma system. $[8,11-13]$ The published literature focused mainly on the causes and outcomes of under-triage. $[11,14,15]$ Building up an organized regional trauma system required a lot of resources without guaranteeing rapid inter-hospital transfer. $[8,9,16]$ The rural trauma team development course has been reported to decrease the time for patient transfer; the risk of death, however, was not reduced as expected.[10,17, 18] To the best of our knowledge, our study firstly demonstrated that regular feedback on the inter-hospital transfer might contribute to the reduction of mortality risk.

Hemorrhage is the main cause of preventable death of trauma patients. [19-21] Early blood transfusion serves as a bridging measure to definitive hemostasis procedures so that the mortality risk could be decreased. [22] In fact, our feedback for regional hospital emphasizes not only the importance of early blood transfusion, but also the transportation of blood component. To solve these problems as a whole, we break down the issues into small steps and optimize each of them. We have set up the protocol as to early notification of blood bank for $\mathrm{O}+$ blood preparation, and the personnel for blood component 
transportation from the blood bank to the emergency department or the operating room. These experiences were shared with the regional hospital. This explain why the mortality risk was decreased in our study but not in other study. $[10,17]$

The context of feedback was not only lecture or presentation on the outcomes of the transferred patients, but also communication and interaction of emergency department physicians and trauma surgeons on the transfer detail. The feedback is supposed to be innovative and problem-solving instead of faultfinding and anxiety-provoking. In the process of monthly feedback, we acknowledged that one-way feedback from the tertiary trauma center focusing on the backend processing more often becomes captious or hypercritical than constructive in terms of a rapidly responsive and effective trauma system. Breaking down the transfer issue into small steps highlighted the emerging problem and enhanced the will of cooperation especially when the triage took right measure to the initial resuscitation. Interaction from both sides helped emergency physicians and trauma surgeons comprehend the patient evaluation at the scene and the rationale of decision making on hemostasis, compensating the gap of judgement and enhancing the will of cooperation.

Some limitations do exist in our study. Selection bias was inevitable because of the retrospective nature of our study. The small number of study cohorts in a single tertiary center was another disadvantage, and the shortage of medical personnel at the emergency department in regional hospital might be overlooked. Since inter-hospital transfer occurred to severely injured yet salvageable patients, patients presenting with cardiopulmonary collapse and dismal outcome might be neglected. Further investigation on a larger population among different tertiary centers is mandatory to consolidate our conclusion.

\section{Conclusions}

Regular feedback on the inter-hospital referrals improved the quality by facilitating blood transfusion before patient transfer. The mortality risk was also reduced in patients with major trauma.

\section{Abbreviations}

IHTD

inter-hospital transfer duration; ED:emergency department; TSBT:time span before blood transfusion; PRBCs:packed red blood cells; ISS:injury severity score

\section{Declarations}

\section{Ethics approval and consent to participate}

This retrospective study was approved by the institutional review board of National Cheng University Hospital (B-ER-109-036).

\section{Consent for publication}


Not applicable

\section{Availability of data and materials}

The datasets used and analyzed during the current study are available from

the corresponding author on reasonable request

\section{Competing interests}

The authors declare that they have no competing interests

\section{Funding}

Not applicable

\section{Author Contributions}

CJW: literature search, data analysis, manuscript writing, study design. THY: literature search, data collection, data interpretation, manuscript editing. KHK: literature search, data interpretation, data collection. CHW: data interpretation, literature search. STY: data collection, data interpretation. YTY manuscript writing, critical revision, data interpretation. YSS: study design, data interpretation, critical revision.

\section{Acknowledgements}

We are grateful to Dr. Liang-Yi Wang and Ms. Chih-Hui Hsu for providing the statistical consulting services from the Biostatistics Consulting Center, Clinical Medicine Research Center, National Cheng Kung University Hospital.

\section{References}

1. Mathers CD, Loncar D. Projections of global mortality and burden of disease from 2002 to 2030 . Plos med 2006; 3: e442.

2. Organization WH. Injuries and violence: the facts 2014. 2014.

3. MacKenzie EJ, Rivara FP, Jurkovich GJ et al. A national evaluation of the effect of trauma-center care on mortality. New England Journal of Medicine 2006; 354: 366-378.

4. Alao DO, Cevik AA, Eid HO et al. Trauma system developments reduce mortality in hospitalized trauma patients in Al-Ain City, United Arab Emirates, despite increased severity of injury. World journal of emergency surgery 2020; 15: 1-6.

5. Gabbe BJ, Biostat GD, Lecky FE et al. The effect of an organized trauma system on mortality in major trauma involving serious head injury: a comparison of the United kingdom and victoria, australia. Ann Surg 2011; 253: 138-143. 
6. Twijnstra MJ, Moons KG, Simmermacher RK, Leenen LP. Regional trauma system reduces mortality and changes admission rates: a before and after study. Ann Surg 2010; 251: 339-343.

7. Cairns CB, Glickman SW. Time makes a difference to everyone, everywhere: The need for effective regionalization of emergency and critical care. Annals of emergency medicine 2012; 60: 638-640.

8. Harrington DT, Connolly M, Biff WL et al. Transfer times to definitive care facilities are too long: a consequence of an immature trauma system. Ann Surg 2005; 241: 961-966; discussion 966-968.

9. Svenson J. Trauma systems and timing of patient transfer: are we improving? Am J Emerg Med 2008; 26: 465-468.

10. Malekpour M, Neuhaus N, Martin D et al. Changes in rural trauma prehospital times following the Rural Trauma Team Development Course training. The American Journal of Surgery 2017; 213: 399404.

11. Haas B, Gomez D, Zagorski B et al. Survival of the fittest: the hidden cost of undertriage of major trauma. J Am Coll Surg 2010; 211: 804-811.

12. Garwe T, Cowan LD, Neas B et al. Survival benefit of transfer to tertiary trauma centers for major trauma patients initially presenting to nontertiary trauma centers. Acad Emerg Med 2010; 17: 12231232.

13. Feazel L, Schlichting AB, Bell GR et al. Achieving regionalization through rural interhospital transfer. The American journal of emergency medicine 2015; 33: 1288-1296.

14. Deeb A-P, Phelos HM, Peitzman AB et al. Disparities in rural versus urban field triage: risk and mitigating factors for undertriage. Journal of Trauma and Acute Care Surgery 2020.

15. Hill AD, Fowler RA, Nathens AB. Impact of interhospital transfer on outcomes for trauma patients: a systematic review. J Trauma 2011; 71: 1885-1900; discussion 1901.

16. Bulger EM, Kastl JG, Maier RV. The history of Harborview Medical Center and the Washington State Trauma System. Trauma surgery \& acute care open 2017; 2: e000091.

17. Dennis BM, Vella MA, Gunter OL et al. Rural Trauma Team Development Course decreases time to transfer for trauma patients. Journal of Trauma and Acute Care Surgery 2016; 81: 632-637.

18. Kappel DA, Rossi DC, Polack EP et al. Does the rural trauma team development course shorten the interval from trauma patient arrival to decision to transfer? Journal of Trauma and Acute Care Surgery 2011; 70: 315-319.

19. Teixeira PG, Inaba K, Hadjizacharia P et al. Preventable or potentially preventable mortality at a mature trauma center. Journal of Trauma and Acute Care Surgery 2007; 63: 1338-1347.

20. Gruen RL, Jurkovich GJ, McIntyre LK et al. Patterns of errors contributing to trauma mortality: lessons learned from 2594 deaths. Annals of surgery 2006; 244: 371.

21. Cales RH. Trauma mortality in Orange County: the effect of implementation of a regional trauma system. Annals of emergency medicine 1984; 13: 1-10.

22. Meyer DE, Vincent LA, Fox EE et al. Every minute counts: time to delivery of initial massive transfusion cooler and its impact on mortality. The journal of trauma and acute care surgery 2017; 
Figures

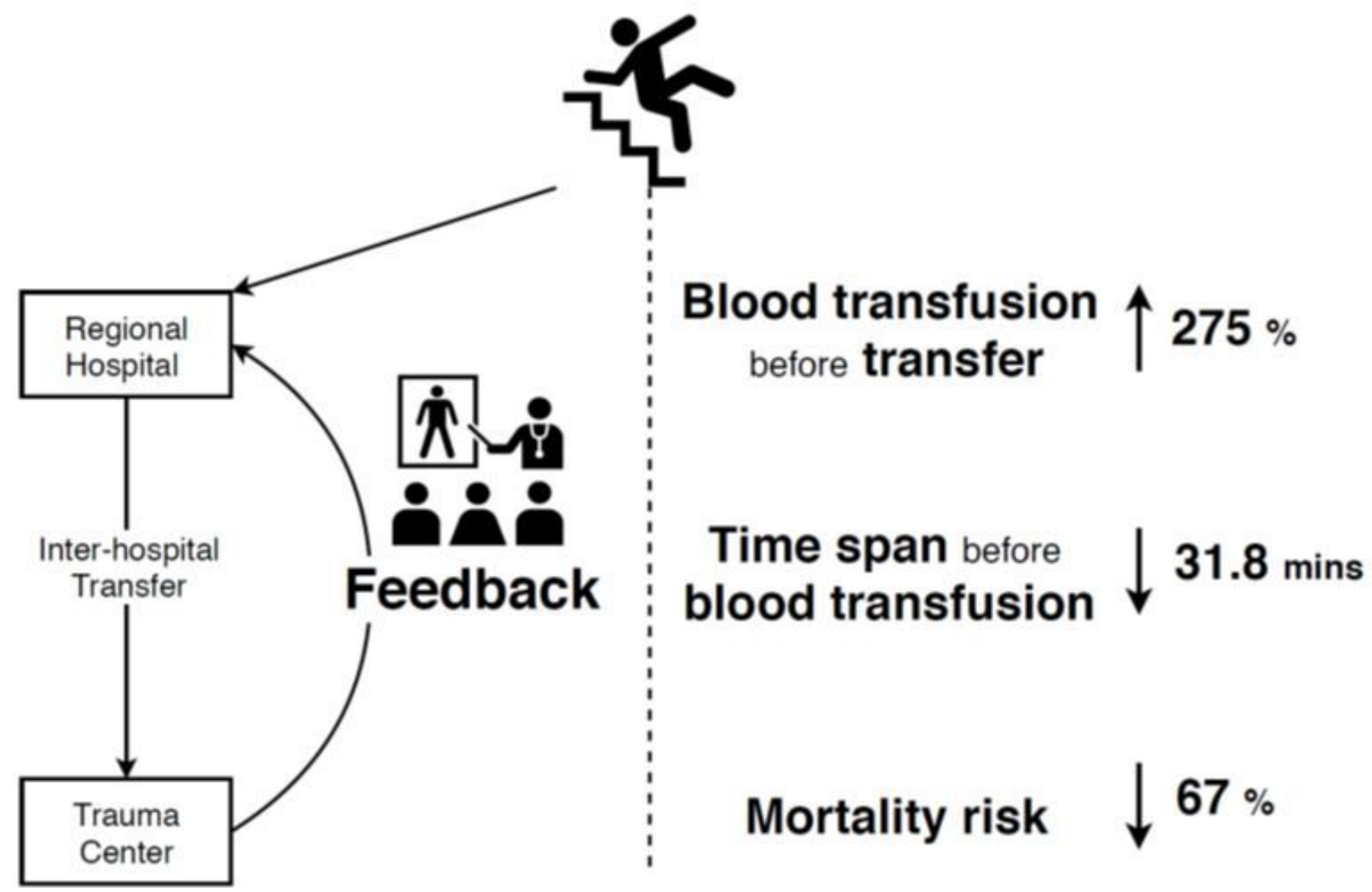

Figure 1

Illustration of the effect of inter-hospital feedback. 